\title{
Construindo, aprendendo e brincando com a catapulta
}

\author{
Agatha P. de Almeida* Daniela da R. Teza* ${ }^{*}$ Vinícius Nicolau* \\ Universidade Tecnológica Federal do Paraná - UTFPR \\ 80230-901, Campus Curitiba, Curitiba, PR
}

\author{
Vitor José Petry \\ Universidade Tecnológica Federal do Paraná - UTFPR \\ Departamento de Matemática \\ 80230-901, Campus Curitiba, Curitiba, PR \\ E-mail: veptry@utfpr.edu.br
}

\author{
Karine A. S. Biazi \\ Colégio Estadual Julia Wanderley \\ 80440-020, Curitiba, PR \\ E-mail: karine_biazi@yahoo.com.br
}

\section{RESUMO}

"A geometria existe por toda parte. [...] É preciso, porém, olhos para vê-la, inteligência para compreendê-la e alma para admirá-la." Malba Tahan

Durante o $6^{\circ}$ ano do Ensino Fundamental o aluno tem contato com os conceitos básicos da geometria - ponto, reta e plano. Apesar de já conseguir abstrair alguns conceitos, percebe-se certa dificuldade, por parte dos alunos, em enxergar a aplicabilidade de tais conteúdos, fato que pode ser justificado muitas vezes pela forma com que os conteúdos são expostos e ensinados. Neste caso, a utilização de metodologias diferenciadas e diversificadas proporciona um aprendizado mais significativo e dinâmico com apropriação de conceito.

\begin{abstract}
No processo de construção do conhecimento, as crianças se utilizam as mais diferentes linguagens e exercem a capacidade que possuem de terem idéias e hipóteses originais sobre aquilo que buscam desvendar. Nessa perspectiva as crianças constroem o conhecimento a partir das interações que estabelecem com as outras pessoas e com o meio em que vivem. $\mathrm{O}$ conhecimento não se constitui em cópias da realidade, mas sim, fruto de um intenso trabalho de criação, significação e ressignificação. (MINISTÉRIO DA EDUCAÇÃO E DO DESPORTO, 1998, p. 21)
\end{abstract}

Durante o planejamento das atividades da equipe do Programa Institucional de Bolsas de Iniciação à Docência (PIBID) que atua no Colégio Estadual Júlia Wanderley optou-se por realizar algumas oficinas, objetivando propiciar aos alunos um momento lúdico visando a facilitação do processo aprendizagem. Havia uma imensidão de ideias e, por isso foram necessários diversos encontros para discussão e definição das atividades a serem desenvolvidas. Optou-se pela realização de quatro oficinas pedagógicas, uma em cada série do ensino fundamental (do sexto ao nono ano).

As primeiras turmas com as quais trabalhamos foram os sextos anos através de uma oficina desenvolvida a partir da construção de uma catapulta. A oficina foi adaptada de um vídeo, no qual a catapulta era construída utilizando sete lápis de cor, elásticos e um pequeno pedaço de silver tape. Assim, optou-se por uma atividade com materiais de fácil acesso, baixo custo e de fácil confecção, adequando-se ao grau de maturidade das crianças envolvidas. Nosso objetivo com esta oficina era trabalhar com os estudantes um pouco da história da catapulta, e estudar com eles alguns conceitos geométricos e suas representações, que muitos ainda não haviam visto em sala de aula.

Iniciou-se a atividade contextualizando sobre a história e utilização catapulta, seguida da exposição e discussão dos conceitos matemáticos envolvidos. Segundo Azevedo (1979), é importante apresentar à criança situações concretas que a levem a agir, a pensar, a experimentar, a descobrir, e daí, a mergulhar na abstração. De acordo com Vidigal (2002, p. 33), "ter um conhecimento básico de Geometria é importante para a pessoa no dia-a-dia, seja para se orientar, para se comunicar, para apreciar a beleza das formas na natureza e nas artes.

* Bolsistas do Programa Institucional de Bolsas de Iniciação à Docência - PIBID 
Para desenvolver e reforçar o trabalho em equipe, os estudantes foram divididos em grupos de dois a três indivíduos, dependendo do número de alunos na sala. No momento da construção, um bolsista ficou à frente da turma explicando o passo a passo, e os demais ficavam auxiliando os grupos, para todos conseguirem acompanhar a atividade. Após finalizada, cada grupo poderia testar a catapulta ao lançar bolinhas de papel para derrubar latas de refrigerante vazias. Na figura abaixo, pode-se observar o processo de construção e o resultado obtido. Foram trabalhados conceitos e definições referentes a reta, semirreta, segmento de reta, ângulos, polígonos, poliedros, vértices, arestas e planos.

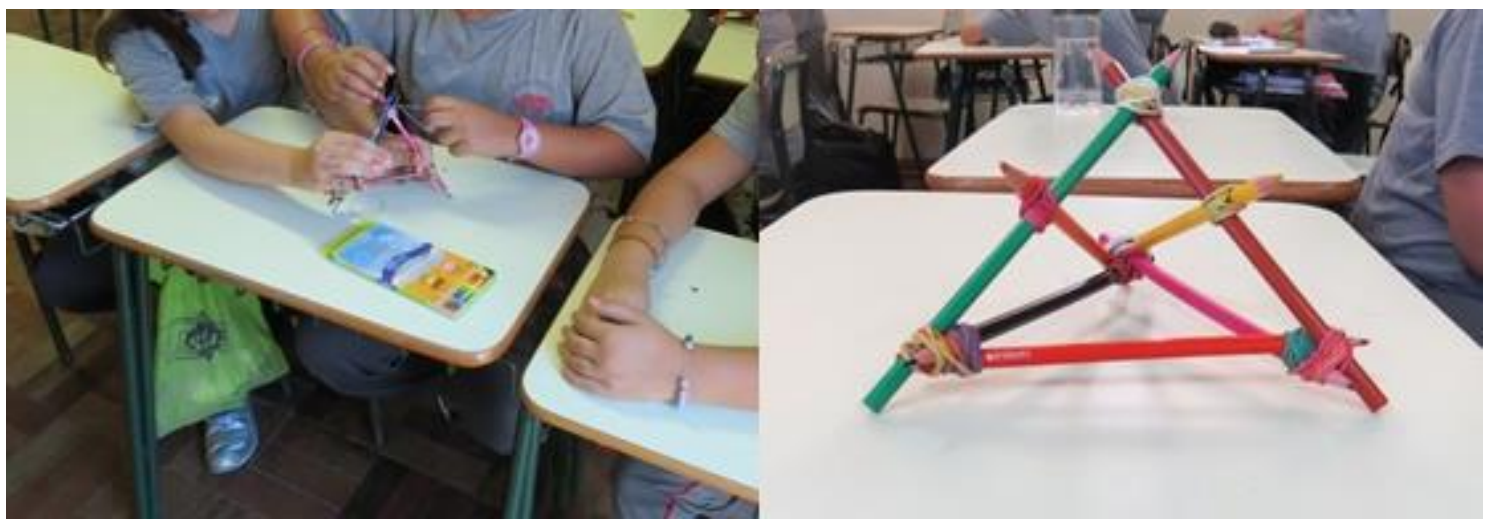

Figura 1: Construção e catapulta finalizada

Avaliamos que o resultado da atividade foi bastante satisfatório, pois constatamos que os alunos perceberam os elementos geométricas na catapulta e fizeram associações com as representações que ocorrem em situações de seu cotidiano. A partir destas representações foi feita a formalização dos conceitos observados. Além disso, o desenvolvimento desta atividade contribuiu com a formação dos bolsistas envolvidos como futuros professores. Este é um dos principais objetivos do programa PIBID, que tem a função de inserir os alunos das licenciatura em escolas públicas.

Palavras-chave: Oficinas, Catapulta, Ensino-aprendizagem

\section{Agradecimentos:}

Agradecemos à Coordenação de Aperfeiçoamento de Pessoal de Nível Superior (CAPES) e ao Colégio Estadual Julia Wanderley.

\section{Referências}

[1] Brasil, Ministério da Educação e do Desporto. Secretaria de Educação Fundamental. Referencial curricular nacional para a educação infantil: introdução. Brasília, 1998. (V. 1, pp. 21-2)

[2] E. D. M. Macedo, Apresentação do trabalho Montessoriano, Ver. de Educação \& Matemática, no. 3, pp. 26-27, (1979).

[3] M. Tahan, O Homem que Calculava, 46 edição, Editora Record, Rio de Janeiro, 1998.

[4] A. Vidigal, et. al, Matemática e Você $5^{a}$ e 6 $6^{a}$ Séries, Saraiva S.A., São Paulo, 2002.

* Bolsistas do Programa Institucional de Bolsas de Iniciação à Docência - PIBID 